\title{
The Editor-in-Chief Writes...
}

\author{
Peter Beaumont ${ }^{1} \cdot$ Costas Soutis $^{2}$
}

Published online: 14 March 2017

(C) Springer Science+Business Media Dordrecht 2017

As I sit down to pen what will be my last column for Applied Composite Materials, I cannot but reflect on what a tremendous privilege it has been as its Founding Editor. I was constantly aware from the beginning of this journey more than 20 years ago of the shared spirit of camaraderie between members of the Editorial Board, many of whom still remain as active members today.

Life as Editor began at Cambridge with a meeting between Dr. Karel Nederveen of Kluwer Academic Publishers and myself. For the next 5 years, Karel showed great faith in supporting me with his frequent visits to Cambridge from Dortrecht, and his regular attendance and generous support of Editorial Board members at international conferences on composite materials was an inspiration. His guidance at Board Meetings at places around the world wherever those international meetings took us was greatly appreciated, invaluable and encouraging.

My time as Editor has been made a lot easier by the support of Professor Costas Soutis as Deputy-Editor, formerly of Cambridge University, now at the University of Manchester. As we approached 25 years of ACMa, which coincides with 5 decades since the discovery of carbon fiber, Costas and I thought it fitting to co-edit a Springer text on the Structural Integrity of Carbon Fiber Composites; the first 50 years published in 2017. Many of those who wrote chapters are members of the Editorial Board. We thank them greatly for their support of ACMa, this Book, and our many exclusive research meetings throughout Europe (on the islands of Capri (Italy) and Madeira (Portugal), and Cambridge), and in the USA (Monterey, California). We remember with fond memories those unique meetings attended by ACMa Editorial Board members and their spouses.

We re-call our special Royal Society Theo Murphy Research Meeting (January 2016) held at Chicheley Hall, Buckinghamshire, UK at which ACMa Editorial Board members presented on Multiscale modeling of the structural integrity of composite material. Our papers were published in a dedicated issue of The Royal Society's journal Phil. Trans. Part A (13th July 2016) edited by

Peter Beaumont

pwb1000@hermes.cam.ac.uk

Costas Soutis

constantinos.soutis@manchester.ac.uk

1 University of Cambridge, Cambridge, Cambridgeshire, UK

2 University of Manchester, Manchester, UK 
Costas and myself. Simultaneously with the beginning of the preliminary stage of planning our Royal Society research meeting, we had already formulated the content and, from our Editorial Board, the dramatis personae for the Springer Book.

Costas and I are conscious that we have held ACMa in stewardship only, respecting the heritage of its Editorial Board that underpins its good work and maintains the highest standard of its publications. We are a group of individuals from all parts of the globe who share a common background, holding a healthy discourse of diverse opinion on any given topic under the umbrella of composite materials. Such variety of talent adds to the richness of our subject producing a stable framework upon which we have worked and continue to work together in an atmosphere of mutual respect.

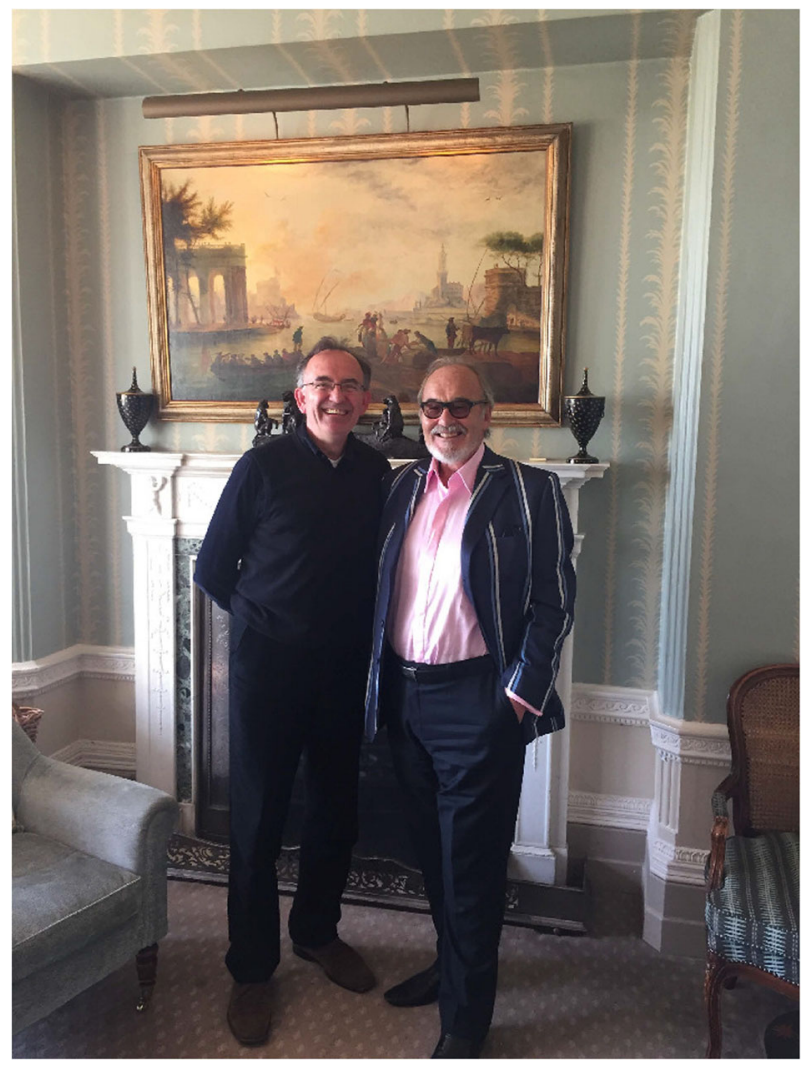

The Editors at a summer luncheon (2016) celebrate the completion of their Book.

Published by Springer (2017). 